\title{
НАЛОГОВЫЙ КОНТРОЛЬ В СОВРЕМЕННЫХ УСЛОВИЯХ РАЗВИТИЯ ПЛАТЕЖНЫХ СИСТЕМ
}

\author{
(C) 2019 Асеев Дмитрий Владимирович \\ кандидат социологических наук, доцент кафедры налогов и налогообложения \\ Самарский государственный экономический университет, Россия, Самара \\ E-mail:d.v.aseev@mail.ru \\ (c) 2019 Цельникер Григорий Феликсович \\ кандидат юридических наук, доцент кафедры публичного права \\ Самарский государственный экономический университет, Россия, Самара \\ E-mail: grigorij-celniker@ya.ru
}

В условиях быстрого развития и глобализации платежных систем, перед налоговыми органами возникают новые насущные задачи, одна из которых это совершенствование механизма налогового контроля и использование новых цифровых технологий при осуществлении фискальной функции. В условиях появления новых финансовых отношений принципиально важно не допустить «запаздывания» одновременного развития систем налогового контроля. В статье обсуждается связанная с этими процессами проблематика. В статье подчеркивается, что в условиях роста рынка криптовалют можно наблюдать рост интереса налоговых служб к налогоплательщикам в этой области правоотношений и рост спроса на новые механизмы налогового контроля. Специфика использования криптовалюты и инструменты анонимизации её пользователей усложняют налоговый контроль в отношении сделок с данным активом, что накладывается на общую проблему сложности налогового контроля в отношении электронной торговли. Несмотря на высокую актуальность выбранной темы степень её разработки пока ещё недостаточно высока, хотя в отдельных работах авторов уже обсуждается отношение законодателей стран к криптовалюте и исследуется опыт зарубежного налогового контроля. В статье анализируется зарубежный опыт (Канада, Финляндия, США) использования методов налогового контроля в отношении сделок с участием криптовалют. На примере конфликта Службы внутренних доходов США (IRS) и биржи криптовалют «Coinbase» исследуются границы анонимизации пользователей криптовалюты. Формируется перечень задач, выполнение которых позволит усовершенствовать механизмы деанонимизации пользователей криптовалюты и отечественного налогового контроля за сделками с участием криптовалют.

Ключевые слова: налоговый контроль, криптовалюта, налогоплательщики, налоговая служба, персональные данные, уклонение от уплаты налогов

В условиях быстрого развития и глобализации платежных систем, перед налоговыми органами возникают новые задачи, одна из которых это совершенствование механизма налогового контроля и использование новых цифровых технологий при осуществлении фискальной функции.

Развитие современных технологий работы с информацией отражается не только на механизмах налогового контроля, но и приводит к возникновению и развитию новых активов криптовалют.

В условиях роста рынка криптовалют можно наблюдать рост интереса налоговых служб к налогоплательщикам в этой области правоотно- шений и спрос на новые технологии налогового контроля.

Ещё в 2016 году, до реформ и попыток введения в закон понятий “цифровые права” (норма вступает в действие с 01.10.2019 г.) и “цифровые финансовые активы” (законопроект, посвященный данному понятию, находится на рассмотрении на втором чтении Государственной Думы) в Письме ФНС России от 3 окт. 2016 г. N OA-1817/1027 служба отметила, что, несмотря на наличие в ст. 27 Федерального закона от 10.07.2002 N86-Ф3 запрета на введение и выпуск денежных суррогатов, запрета на сделки с использованием криптовалюты в законодательстве нет [3].

Специфика использования криптовалюты и 
инструменты анонимизации её пользователей усложняют налоговый контроль в отношении сделок с данным активом, что накладывается на общую проблему сложности налогового контроля в отношении электронной торговли [4]. Традиционные методы борьбы с уходом от уплаты налогов неэффективны, когда речь идет об операциях с биткоинами [10].

Однако, успешный опыт по деанонимизации пользователей криптовалюты есть. Так, Налоговое агентство Канады, говорило о наличии инструментов доступа в своём специальном подразделении (возможно через площадки обмена валюты), к персональным данным участников сделок с криптовалютой [1]. Как показывают сообщения трейдеров и заявления самой CRA в марте 2019 г., заявления о наличии инструментов доступа налоговой службы имели под собой основания [8], ряду пользователей были разосланы вопросники, в которых их просили подробно описать их участие в пространстве криптовалют. За отдельными вопросами читалось желание закрепить успехи деанонимизации (в вопроснике были вопросы об участии обменниках, запрашивающих персональные данные, запрашивались сведения об использовании услуг смешивания криптовалют [6]).

Служащие финской Налоговой Администрации обнаруживают неплательщиков налогов из доходов от продажи криптовалют путем сопоставления поступившей к ним из различных источников информации с отчетной налоговой информацией. Главный инспектор Тимо Пуиро из отдела корпоративного налогообложения Налоговой Администрации Кауппалехти в апреле 2018 г. заявлял, что Финляндия занимает лидирующие позиции в аналитике, связанной с биткоинами. В налоговом ведомстве утверждали, что владеют множеством способов идентификации налогоплательщиков, с использованием, в том числе, информации о платежных операциях [9].

Налоговое агентство Испании пыталось выявлять персональные данные неплательщиков налогов из доходов от продажи криптовалют через запросы в банки, криптовалютные обменники, операторам криптоматов и в организации, принимающие платежи в криптовалюте [1].

Подобная практика в США привела к конфликту Службы внутренних доходов США (IRS) и биржи криптовалют «Coinbase» в конце 2016 года. Запрос IRS информации о пользователях натолкнулся на сопротивление «Coinbase», которые указывали, что фактически запрос требовал раскрытия всех данных по счетам всех клиентов, то есть являлся чрезмерным и необоснованно широким и затрагивал интересы добросовестных налогоплательщиков. Б. Армстронг, глава «Coinbase», пояснял, что более разумным вариантом было бы использование того же стороннего механизма отчетности, который использовали брокерские фирмы Fidelity и Charles Schwab: формы 1099-В [5]. В суде требование налоговой было удовлетворено частично: Coinbase удалось сократить перечень запрашиваемых сведений (ИНН, имя, дата рождения, адрес, записи активности счета, все периодические выписки счета или счета (или эквивалент).

Помимо запросов, IRS использует программное обеспечение для отслеживания транзакций и напоминает держателям криптовалют платить свои налоги посредством подачи деклараций [2].

Отдельные страны пытаются перенять удачный опыт налоговых служб. В декабре 2017 года южноафриканская налоговая служба сообщила о ведении переговоров с рядом технологических компаний (которые проводили аналогичную работу для Канады и Великобритании), какие могли бы помочь в более эффективном отслеживании сделок с криптовалютой [11].

В целом, уже накопилась достаточно большая международная практика контроля криптовалют, которой может воспользоваться ФНС РФ. Знания об уязвимостях криптовалюты, позволяет определить адресатов запросов налоговой службы. Одним из таких уязвимых мест, относят то, что привязка личных данных к криптовалютным транзакциям происходит на этапе совершения покупок, при выводе средств в оффлайн, при конвертации криптовалюты через биржу в традиционные деньги.

Отследить цепочку блоков транзакций от момента выпуска криптовалюты до текущей транзакции поможет специальное программное обеспечение: размещённая в сети Интернет Blockchain Info, программное обеспечение Chainalysis, Inc., Elliptic Enterprises Limited, CipherTrace. Продукцию трёх компаний используют службы и правоохранительные органы США, причём на первом месте по расходам на такое ПО идёт налоговая служба [7].

Необходимо программное обеспечение, которое могло бы отечественным налоговым инспекторам осуществить кластеризацию (связь 
биткоин-адресов), а также может связывать адреса для сдачи криптовалютой, с адресами входа и (или) выхода криптовалюты, проводить «анализ распространения», количественный и временной анализ сумм и времени транзакций. Следует также разработать программное обеспечение, позволяющее справляться с сервисами VPN, Tor и т.д, которые используются для сокрытия операций с криптокошельками.

Не менее остро стоит и задача выроботки инструментов противодействия деятельности миксеров криптовалют (например, Blender, PrivCoin, SmartMix, Cashshuffle, Wasabi).

В качестве побочной задачи стоит поиск пу- тей выявления скрывающихся налогоплательщиков, использующих такие криптовалюты как Dash, Monero, Zcash, отличающиеся от Bitcoin более сильной защитой анонимности. Данные и подобные криптовалюты будут активно использоваться, при усилении мер налогового контроля в отношении таких популярных криптовалют как Bitcoin, Ethereum.

Выполнение таких важных задач невозможно без обращения к зарубежному опыту, без международного сотрудничества налоговых служб и межведомственного взаимодействия с Центральным Банком России.

\section{Библиографический список}

1. Воловик Е. Брать налоги с криптовалют. Почему бухгалтеры опасаются работать с криптовалютами // Финансовая газета, 2018, № 20. СПС “Консультант Плюс” (дата обращения 21.06.2019 г.).

2. Корниенко Н.Ю., Минина Е.Е., Королев Г.А., Митрофанова Е.А. Налогообложение доходов частных лиц, полученных от операций с финансовыми инструментами в ЕАЭС (14 Март, 2019) // URL: http://dx.doi.org/10.2139/ ssrn.3352665 (дата обращения: 21.06.2019).

3. Письмо Федеральной налоговой службы от 3 октября 2016 г. N OA-18-17/1027 Об операциях, связанных с приобретением или реализацией криптовалют с использованием валютных ценностей (иностранной валюты и внешних ценных бумаг) и (или) валюты РФ // URL: http://base.garant.ru/71584452/\#ixzz5sArJ3acy (дата обращения 21.06.2019 г.).

4. Цельникер Г.Ф., Прокудина Н.О. Проблемы налогообложения торговли в интернете (интернет-бизнес) // Международный журнал гуманитарных и естественных наук, 2018, № 12-2. С. 161-163.

5. Armstrong B. Coinbase and the IRS. URL: https://medium.com/@barmstrong/coinbase-and-the-irsc4e2e386e0cf\#.4z5plqk7r (дата обращения: 21.06.2019).

6. Bitcoin Investors Targeted With Audits By Canada’s Federal Tax Agency // URL: https://www.forbes.com/sites/ ktorpey/2019/03/06/bitcoin-investors-targeted-with-audits-by-canadas-federal-tax-agency/\#7fcde249656e (дата обращения 21.06.2019 г.).

7. Blockchain Analysis Spending by US Government Agencies Has Tripled in 2018 // URL: https://www. crowdfundinsider.com/2018/09/139486-blockchain-analysis-spending-by-us-government-agencies-has-tripledin-2018/ (дата обращения 21.06.2019 г.).

8. Canada's tax agency asks cryptocurrency investors for 10 year trading history // URL: https://thenextweb.com/ hardfork/2019/03/07/canadas-tax-agency-asks-cryptocurrency-investors-for-10-year-trading-history/ (дата обращения 21.06.2019 г.).

9. KL: Verottaja odottaa jättipottia bitcoin-voitoista - yli 3300 suomalaista tunnistettu // URL: https:// www.arvopaperi.fi/uutiset/kl-verottaja-odottaa-jattipottia-bitcoin-voitoista-yli-3300-suomalaistatunnistettu/121a936a-170a-3538-9ba9-e0ee88826bfb (дата обращения 21.06.2019 г.).

10. Marian O. Are Cryptocurrencies Super Tax Havens? // Michigan Law Review. First Impressions. 2013. Vol. 112. URL: https://papers.ssrn.com/sol3/papers.cfm?abstract_id=2305863 (дата обращения 21.06.2019 г.).

11. Sars looking at tracking Bitcoin and other cryptocurrency trades: report // URL: https://businesstech.co.za/news/ banking/216597/sars-looking-at-tracking-bitcoin-and-other-cryptocurrency-trades-report/ (дата обращения 21.06.2019 г.). 